\title{
THIRD MOLAR INFLUENCE IN ORTHODONTIC CASES*
}

\author{
By Dr. H. L. Morehouse, Spokane, Wash.
}

T SELECTING this subject for my contribution to this meeting, I did so 1 because it was the one I had planned on presenting to you last year. In the meantime, however, Dewey published an article on the subject in the September issue of the International Journal of Orthodontia, but I still feel this subject needs further emphasizing. This I shall endeavor to do with a short paper and reports of a few cases in my own experience, where the third molars were extremely active.

From a dental standpoint, the question of third molar influence does not arise until between eighteen and twenty-five years of age, while from an orthodontic viewpoint, the question should be considered as early as twelve years.

Authorities on comparative anatomy claim that we are gradually evolving to a state where we will eventually be saved all the annoyance of these once essential members. Then think what a pleasure it will be to practice our chosen profession.

If we will watch our preventative cases closely during the period of eruption of the first permanent molars, we will find the same influence being exerted that later gives us trouble from the third. In fact, the pressure is a normal one, as it is nature's way of creating the stimulus necessary for the proper development of the bones of the two dental arches. From a careful study of the attending conditions, as well as the position of the erupting second molars, in Class II Division I cases, I believe we will find that in a great many instances, the action of the second molar will be found to answer the question of the etiology of these cases. In many cases where the second premolars have been locked out, we will find the action of the erupting second molars have forced the firsts mesially in the same manner and with the same result as is later brought about by the action of the third molars. The extent of the damage resulting from these erupting forces, depends on the amount of resistance the teeth anterior to them exert; their shape and form of the cusps, as well as the occlusion of the teeth. In some cases it will be found that the second molar force began very early, with the result that the first molar is occupying the space that belongs to the second premolar. The consequence is that it (second premolar) is either impacted or has been forced out of its normal position in the arch.

In cases where this has occurred, naturally the germ of the third molar has taken a position much further mesially than it otherwise would. If, then, we endeavor to establish normal occlusion without an extraction, the condition will be complicated more than ever. This must have been the experience of James Robertson to whom Weinberger refers in his History of Orthodontia. Robertson published, in the Dental Review, of London, in 1895, an article on

* Read before the Pacific Coast Society of Orthoduntists, San Francisco, Calif., Feb. 18, 1918. 
the Cause of Irregularity of the Teeth in which he says, "The growth and advent of the third molar, when an insufficient space exists for its development is not only a source of great suffering, but frequently the immediate cause of irregularity by the pressure exerted toward the anterior teeth of the mouth which until their development, presented a regular denture." Thus we see that the third molar action is nothing new, but until the last few years it was overlooked by us, as orthodontists, in our anxiety to perfect the treatment and mechanical devices.

I have models of three normally developed cases of about twenty-five years of age where the third molars, in erupting, had forced all the other teeth mesially, crowding one lower incisor out of the line of occlusion; another of about the same age in which the upper centrals were gradually lapping. I advised the extraction of the thirds and a year later the young lady reported that the condition had corrected itself.

It is very apparent that this offending third molar has been the cause of a great many of the failures which, before the advent of the $\mathrm{x}$-ray for diagnosis, we could not account for.

Though this may be the case, it does not necessarily mean that we are not justified in urging the treatment of cases at an early age, (rather the opposite,) for in the treatment of preventive cases, I believe the patient is getting the most for his money and there is less likelihood of any slipping in the future. With the use of the $x$-ray from time to time, we can guard against any mesial movement by means of retainers until such a time as seems best for the removal of the offending members or some other tooth as the case demands. However, in the preventive cases, I feel there will be found the least amount of trouble from this source, for the development is nearer that of $\mathrm{Na}$ ture's work, unassisted by mechanical devices.

About seven years ago, I recall the first case in which I suspected the trouble, that of a young lady eighteen years of age with a Class II, Division 1, Subdivision, in which the upper right cuspid had erupted labially. After a number of months' treatment, I felt that the distal movement was not what it should be, and on x-ray examination, the picture disclosed an impacted upper third molar. This was removed and the case finished splendidly. Later she had the others removed and I experienced no trouble with the retention. This did not arouse my suspicion except for cases of about that age or older.

The next case is another Class II, Division 1 of a girl fifteen for whom no $\mathrm{x}$-ray was taken until the later part of the treatment, disclosing the condition shown in Fig. 1. Here two actions were taking place; the lower thirds were locked distal to the seconds, forcing the first and seconds into position of supraocclusion; the upper thirds were badly impacted above the seconds making it impossible to get normal mesio-distal relation. I had the upper seconds extracted and the lower thirds removed and feel sure that no further trouble will be experienced.

Fig. 2, a Class II, Division 2, case shows trouble only in the lower in which the thirds are causing supraocclusion of the first and second molars, giving the effect of infra-occlusion of the rest of the teeth. The worst of this case was 


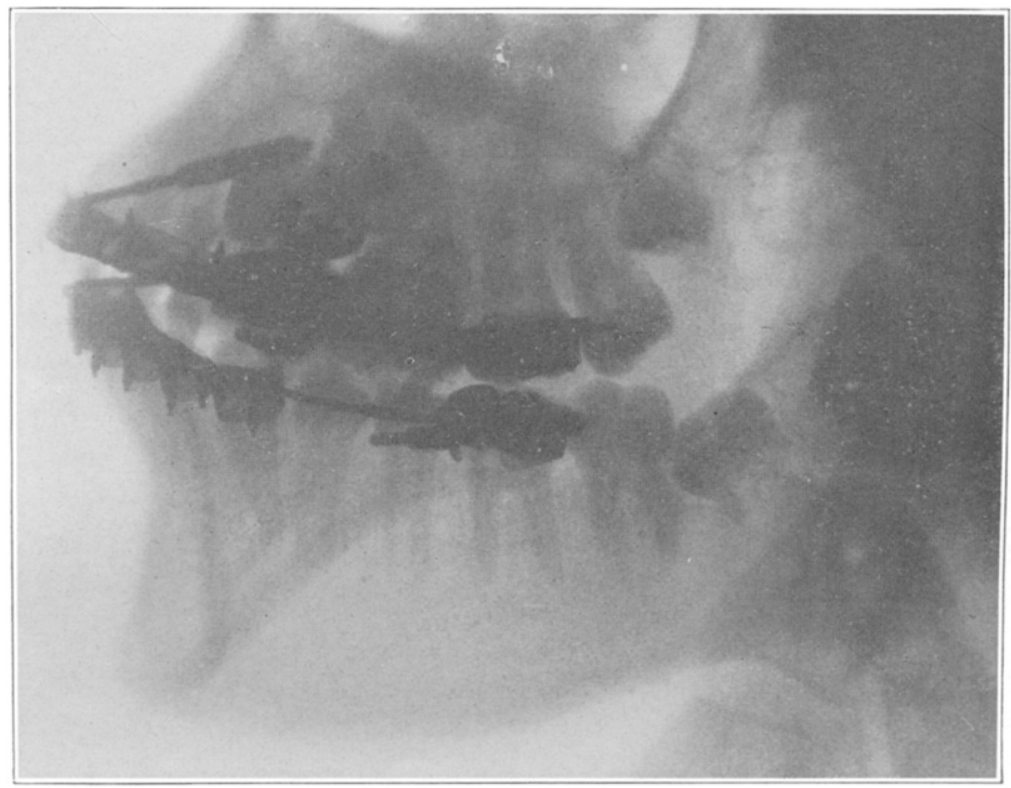

Fig. 1.

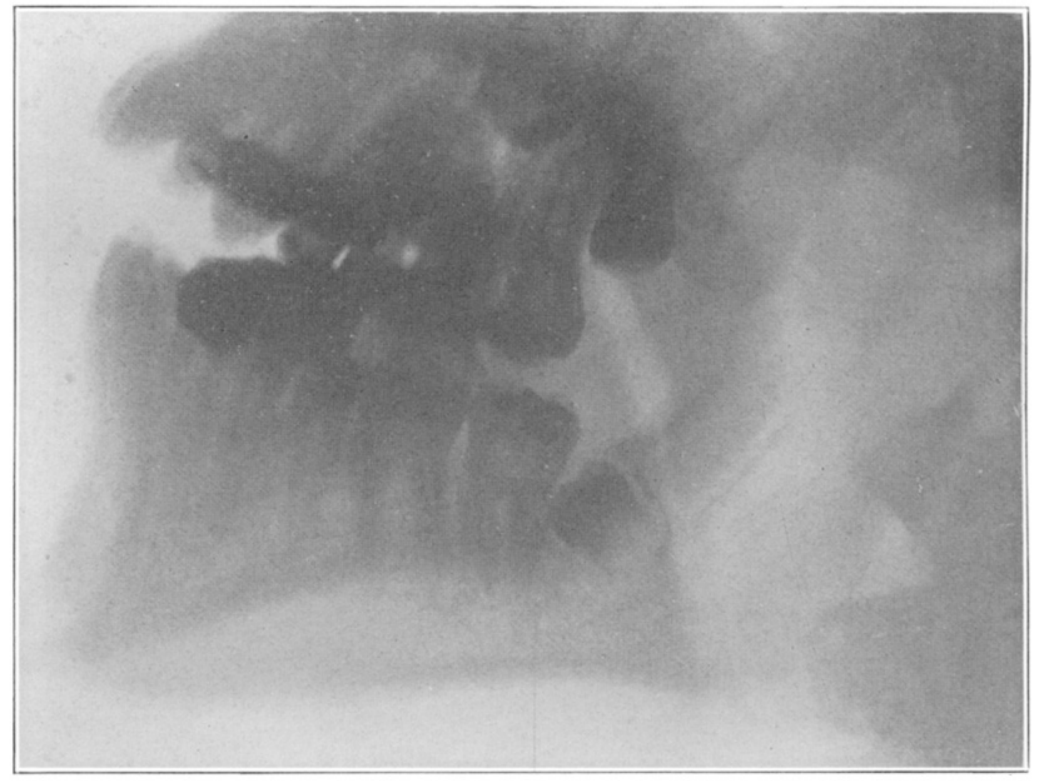

Fig. 2 . 


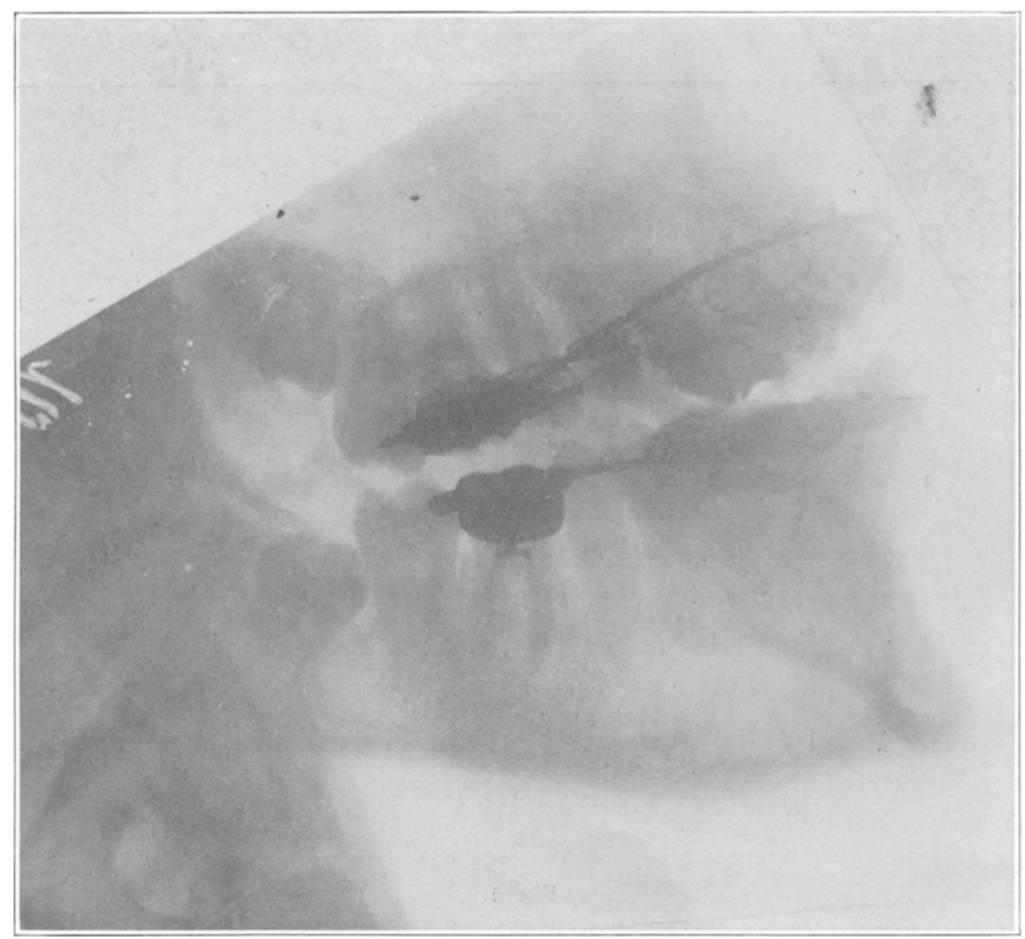

Fig. 3 .

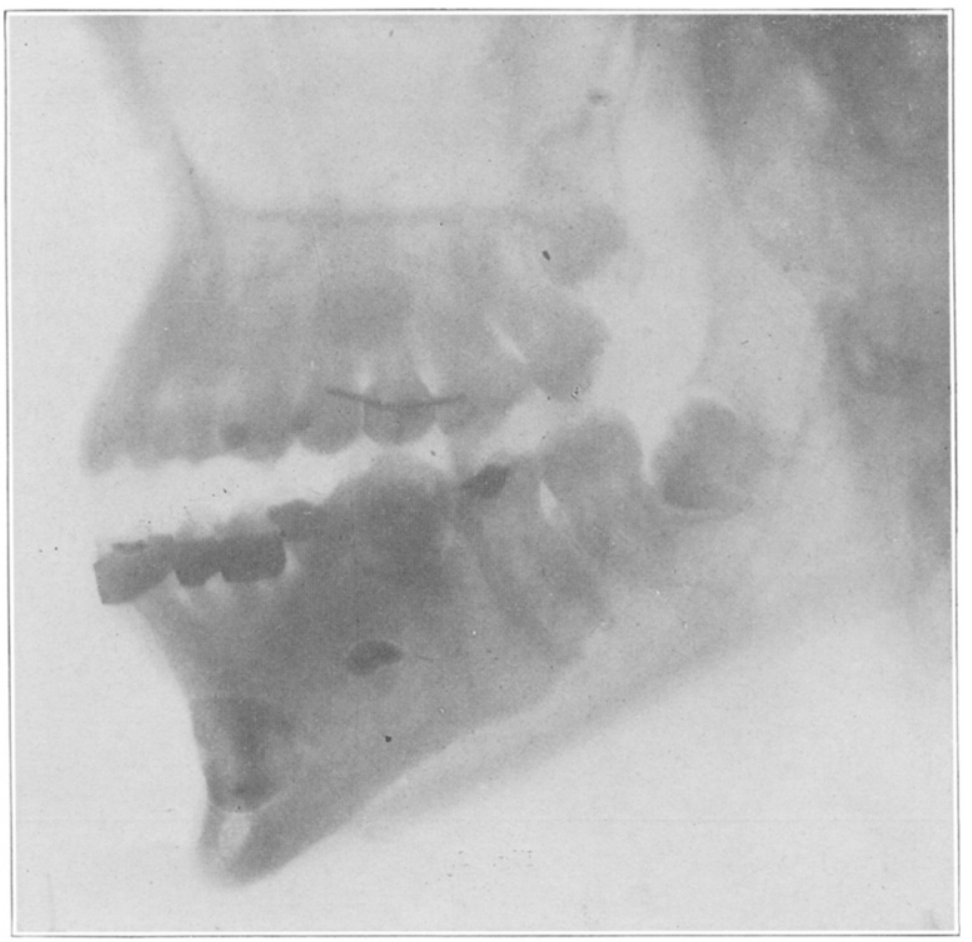

Fig. 4. 


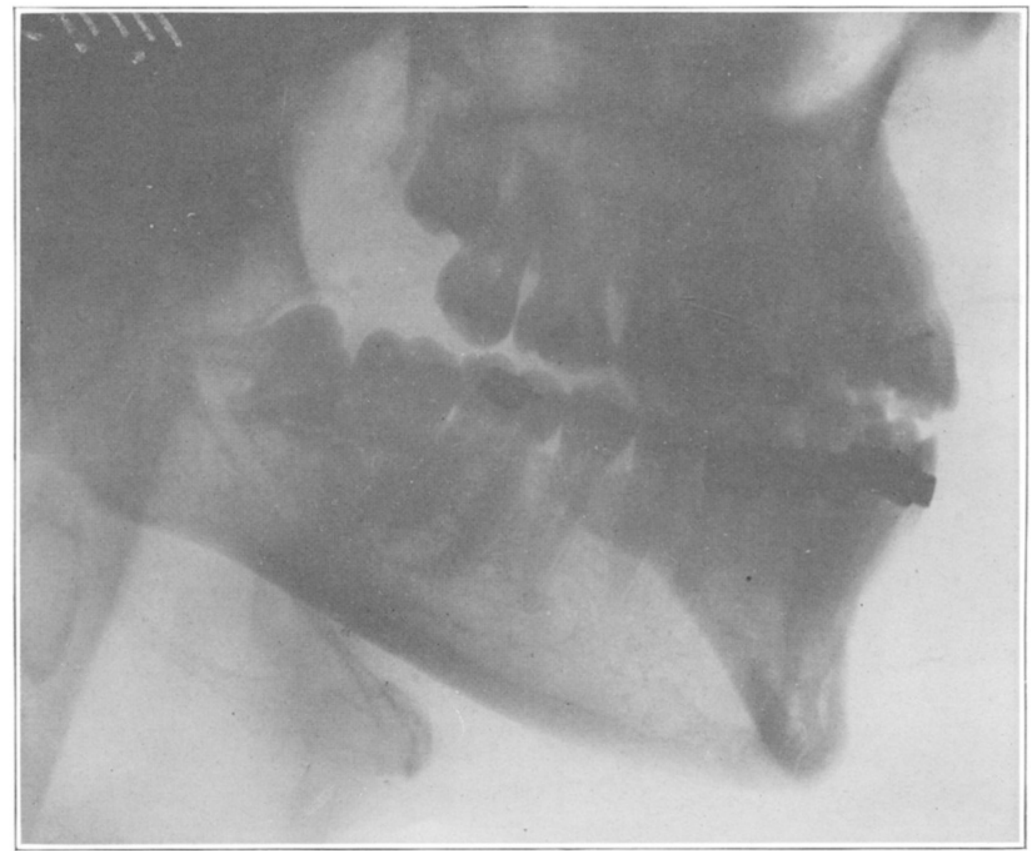

Fig. 5 .

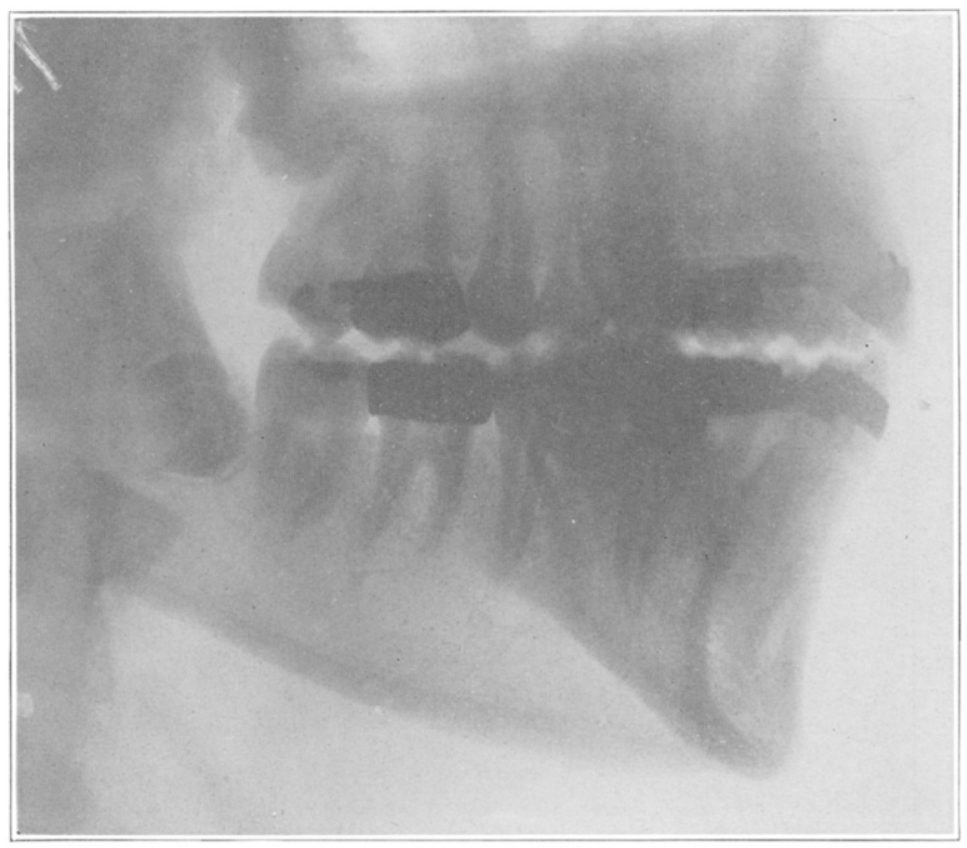

Fig. 6. 


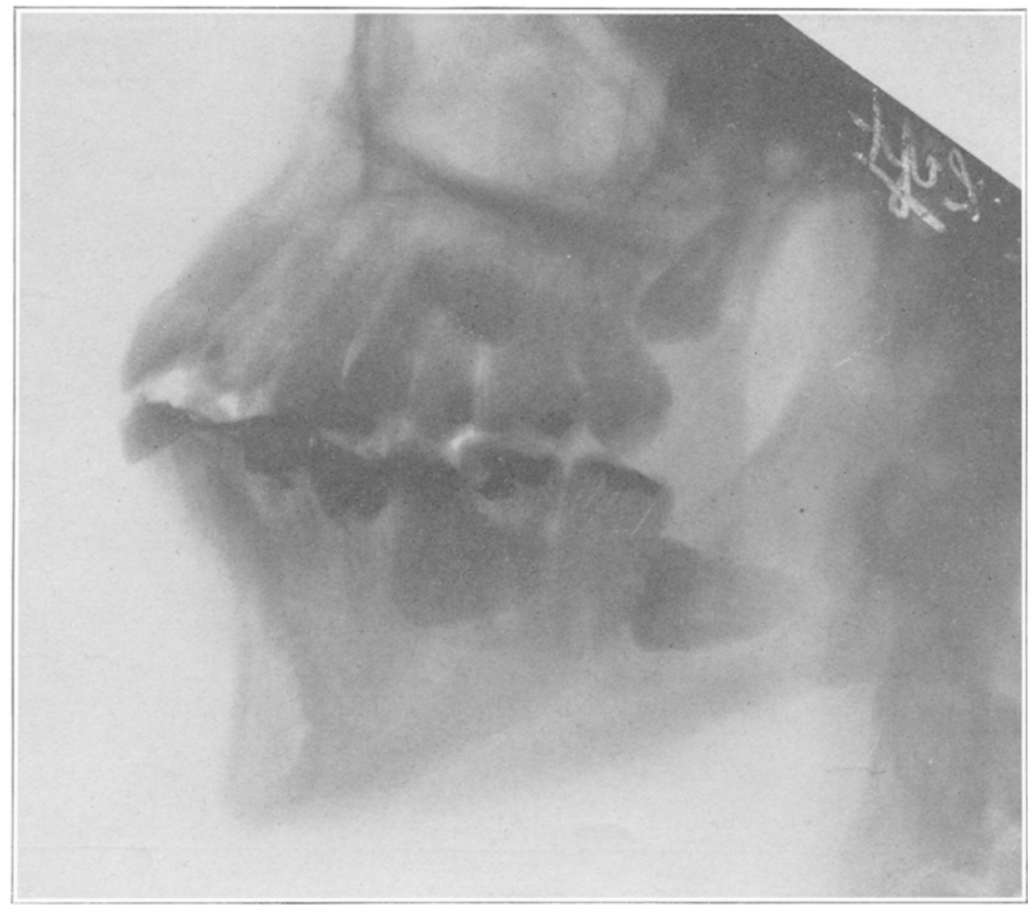

Fig. 7.

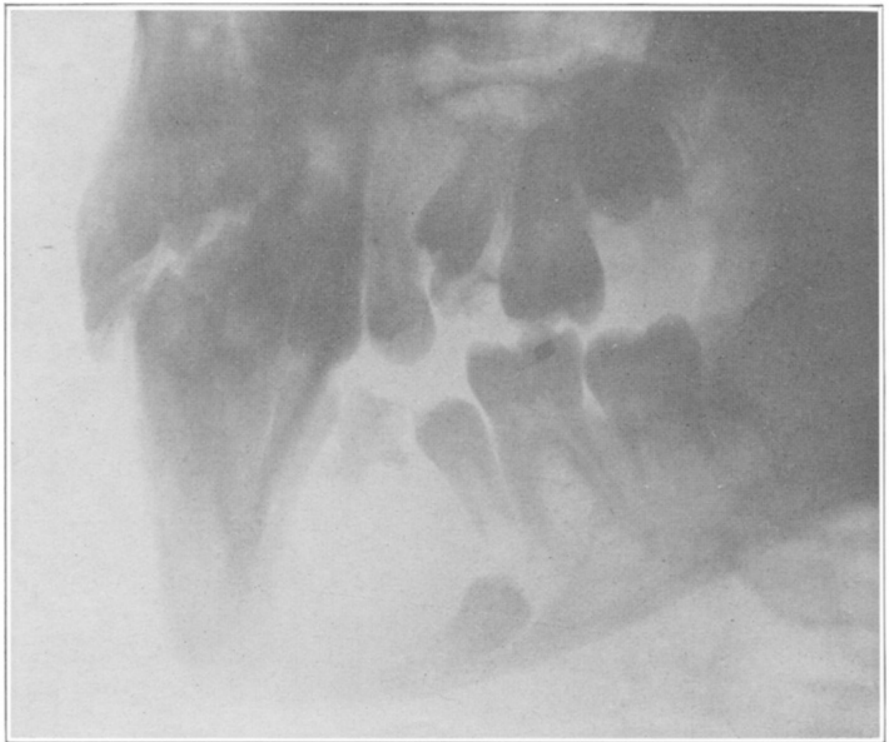

Fig. 8. 
that it did not develop until six months after retention and then the parents delayed having the lower thirds removed until the tissue had been built beneath the other molars, with the result that the case had to be retreated as one of infraocclusion in the incisors.

Fig. 3 is of a Class I case which during treatment developed a supraocclusion of the first and second lower molars, the cause of which is clearly shown in the x-ray, but unlike the second case, the lower thirds were removed at once and the appliances left off for about three months with the result that the teeth settled back to normal themselves and have given no further trouble.

Figs. 4 and 5 are of Class II, Division 2, cases, mutilated on one side with an unerupted upper second premolar on the other. Fig. 4 shows the upper second premolar in position, but the operation of opening the space for the unerupted tooth complicated the impaction on that side. It also shows a badly impacted lower third, which condition is also found in Fig. 5. These lower thirds were causing a movement mesially of all the lower teeth. I had both lower thirds removed, also the upper right second in Fig. 4 and no further trouble is anticipated.

The question will arise in most minds at once, would it not have been better to have waited until the second premolar did erupt and extract that, thus saving the patient the long treatment. This might have been best had the $\mathrm{x}$-ray disclosed the impacted lower thirds at that time. In some ways the condition shown in Fig. 5 answers the question.

Fig. 6 is of a Class I case with the usual prominent cuspids of a boy of thirteen. The father of this boy was a "Doubting 'Thomas," and in order to be certain that nothing went wrong, I had used every precaution in the treatment. After retaining the case for about a year, I removed the upper retention, feeling certain the occlusion would hold the case. Four months later I discovered I was falling heir to a beautiful Class II case and immediately upon $\mathrm{x}$-ray examination the reason was plain; it showed badly impacted upper thirds. It also disclosed the lower thirds in a position which, from experience, I knew would give trouble later, so had those removed also.

Fig. 7 is one of the most disheartening of any I have ever had under treatment. It is a Class II, Division 1 case which I treated some eight years ago. The girl was seventeen years of age. After correction of the case, I held the arches under retention for about two years. They were then gradually removed. The arches showed no signs of buckling for nearly three years, when they started. As soon as I discovered the condition, radiographs disclosed what you see on the screen. The worst of it all is that she refuses to have them removed and I have disclaimed any future responsibility for the case.

Fig. 8 is not one of the third molar trouble, but one which is very seldom encountered, that of a cystic odontoma in a girl nine years old, which I thought might be of interest to some of you.

I feel that radiograms should be taken at regular intervals of six months to a year, according to the condition that shows in the first picture.

In closing, if there are any who have been in doubt as to the trouble these 
impacted third molars can inflict on our young patients, I trust that these few illustrations will have emphasized the danger which lies in wait for them if they do not heed the signs.

\section{DISCUSSION}

Dr. Wm. Cavanagh.-You have listened to one of the papers that should make us glad to be here. To detect just such unseen and unsuspected sources of malocclusion as Dr. Morehouse has pointed out will doubtless save many of us as much time as is required to make the journey to San Francisco and return. I think the paper is deserving of a very thorough discussion.

Dr. Robert Dunn.-It is rather difficult for me to discuss this paper as I am not in a position to do it justice. The Doctor statcs that from the orthodontist's viewpoint the influence of the third molar should be considered about as early as the twelfth year. I believe there are instances where it would be well to consider this matier in patients even younger than that. All with any considerable practice in orthodontia have doubtless had some very sad experiences with third molars. Work carefully done has been upset. Retainers have been removed and the patients have returned to have the appliances replaced and readjusted, and the statement is made, "I was in the care of Dr.

and had my teeth corrected and they would not stay; I am not going back again, etc." Students of comparative anatomy claim the time is coming when we will not be troubled with third molars, but I think this is a dream, and as long as we live we will have third molars to contend with. I do not believe the race is losing any of its teeth.

Dr. Morehouse did not make much reference to Class III cases. I have handled a great number of patients, having this type of malocclusion. It seems to have been my lot to treat many of them. In every one of these cases you can see the influence of the third molar after a certain age. Unless you have those teeth removed you will probably not succeed in completing the treatment of these cases for a number of years. Even if the teeth are removed, in case it is not done early enough, the tendency is to revert.

One point not mentioned in the paper is a combination of influence of the third molar and bad dental restorations. Gentlemen, there are many failures in orthodontia due to faulty dental restoration. A wrongly formcd inclined plane,-incorrect contact points, etc., and you have the pressure of the third molar on the second molar, tending to move the second molar lingually, or buccally. The first permanent molar, or premolar tooth may be affected.

Dr. Morehouse spoke of impacted premolars. The question arises, what are we going to do with those cases?. In case the third molars are not already impacted, will they become so through our operations to make space for the premolars?

$D r$. John $R$. McCoy. - I think that as has already been stated this paper is going to be worth a great deal to us. I have always realized that the third molar must have its influence in causing a recurrence of malocclusion, and I can look over some of my cases right now and see where the extraction of those teeth may be of immense value.

Speaking of Class III cases, I believe from now on there will be more and more of those lower third molars removed. I shall attend to it in my own practice, as a matter of precaution.

The value of the $x$-ray in orthodontia is certainly represented in this work, and $I$ think most of us have used it far too little, usually because it puts the patient to a little expense or trouble, when probably it would save the patient a great deal of trouble and ourselves much expense if we used it more.

Dr. Suggett.-I think Dr. Morehouse's paper will save me a lot of trouble in the future. I think the idea we got a few years ago of the maximum number of teeth in the mouth, with every tooth in its place, was a bit exaggerated, and we have been afraid of breaking the rule and of being independent enough to remove any teeth. There are cases where the removal of the second molar will result in its replacement by the third molar, and in other instances the third molar should be removed. I have had many cases where I am sure such a pracedure would have saved me much trouble. Two years after treatment I have had buckling up of the cases, and a return of the teeth to their abnormal positions, due, I am sure, to the influence of the third molars.

Another interesting question in this connection is, When does our responsibility cease? The question is a rather debatable one.

Dr. Mann.-I think the Society is to be congratulated in having a paper of this sort presented to it. I can now see how much trouble might have been avoided in my own 
practice earlier had I come into the light as Dr. Morehouse has done. I however agree very fervently with Dr. Dunn, that these cases should be observed even earlier than twelve years of age. In one case recently under observation in my practice, that force was obviously in operation at the age of seven to eight years to such a great extent that the first molar was impacted behind the second deciduous molat and the second deciduous molar had become eroded so that a shelf was formed which held the first molar in an impacted position, and did not permit of its eruption.

As to the question of the restoration of lost structure, mesio-distal diameters, etc., I think the greatest trouble we have is what is known as "plus contact points." It is a method followed by dentists who are doing what is now known as very modern dental restoration. It seems to me if a better understanding of normal mesio-distal diameters was had among dentists, we probably would have much less trouble in the question Dr. Dunn brought up.

Dr. James D. McCoy-Mr. Chairman: The baneful effects in these third molars in producing recurrent malocclusion, has been very forcibly brought to my attention in many cases which I have treated. In an attempt to work out some practical method of preventing the trouble, I have frequently made radiograms at the time retainers were adjusted, in order to locate the relationship of these teeth to the second molars, and have impressed this fact on the patients, that the retainers must not be removed until those teeth had either erupted or until their eruption can be foreseen by subsequent radiographic examination and the diagnosis made that they may rot afford any complications. I observe another precaution in all thiese cases that remain under my observation. I construct a retainer on the lower arch from cuspid to cuspid, with a lingual wire extending far enough distally to include the surfaces of the first premolars, - - so that that portion of the lower arch will be supported against the pressure of the lower third molars. I have not experienced much difficulty with the upper third molars, except that these teeth may have influenced the eruption of the upper second molars, pushing them forward and causing them to erupt in buccal relation to the lower teeth.

By the construction of the lower retainer referred to, and impressing the patient, that the retainer must remain until the third molars have erunted, I have avoided many recurrences that formerly I was unable to prevent. Following out our present plan in the office of making a radiographic survey of all cases prior to treatment, as a routine part of the examination, we will discover these complications and be able to avoid trouble very often. Where there is a mixed dentition, with deciduous molars still present, etc, we make radiograms, using the extraoral method, getting an adequate survey of both upper and lower arch, embracing all teeth posterior to the canines, and if the third molars present any complication we can check up on these teeth later.

I think the most common form of recurrence is the trouble to be found in the lower arch in the crowding of the incisors and canines. A number of cases have left my regular care at perhaps the ages of ten to twelve years-with all retainers removed. They have been kept under observation from time to time, seeing them over a period of two or three years,- -long enough to be sure no future trouble would recur. Then. I have seen them three to five years later and found this crowded condition of the lower teeth present, and even although the upper teeth do not bunch up, they are influenced by the relationship of the lower teeth because they usually accommodate themselves to the lower teeth. So that the construction of this little retainer, giving the lower arch support, including the canines and first premolars, saves me a great deal of trouble.

Dr. Carter--Mr. President: My attention has been called to the influence of the third molar in these cases of malocclusion, because of the fact I do a great deal of radiographic work. As a routine in my office, whenever I accept a case for treatment, the first thing I do is to make a complete set of radiograms, and because of this fact, and also becanse of the fact I do radiographic work for members of the profession, the matter under discussion has been of much interest to me.

I have a case in mind where a dentist sent a patient to me to see if I could discover why the second molars har not erupted. The patient was about twenty-five years of age. On making a radiographic examination I discovered the third molars were completely inverted and had depressed the second molars on both sides in the lower jaw. They had locked on the cusps of the second molar, so those teeth never erupted. You could see the influence of the depression. The roots of the teeth were locked just like a bowlegged man, and that happened on both sides.

Dr. Dunn mentioned the influence of imperfect restorations, i. e., as to the mesiodistal diameter of the tooth. I believe a gond many cases of recurrence of malocclusion 
are due to these improper restorations. I have noted many cases of relapse, due I am sure to the causes mentioned here this morning. I have taken a great deal of pleasure in explaining to such patients that have chanced to come under my obscrvation, the reason for the trouble. Naturally they seem to think it the fault of the orthodontist, and because of the fact the dentist does not understand why we have these recurrences I sometimes think it would be a very good thing if we could give the dental profession some education along that line, and then they would not be so prone to blame the orthodontist for cases that may have relapsed.

Dr. Solley.-I would like to ask a question with reference to the last case that Dr. Logan operated on. Did you see the splint used there?

Dr. Morehouse.-No. He said he reenforced the jaw before operating.

Dr. Cavanagh.-It seems to me this paper would explain why we are disposed to allow the retainers to remain longer on the lower teeth than the upper. Impactions of the third molars occur more frequently in the lower arch than in the upper, and the anterior teeth are often crowded back into imperfect alignment in spite of proper retention. It occurs to me now that perhaps the third molar has been causing many of my complications, and I shall patronize the radiographer more often hereafter.

Dr. Morehouse. - With regard to the point spoken of by Dr. Suggett, as to the absorption of roots, I think we should be very careful not to make too quick judgment as to the radiographic appearances regarding the absorption of impacted teeth. I recall two instances of the discovery of impacted lower third molars, and the radiograms showed as pretty as could be an apparent absorption of the distal surface of the root of the lower second molars-a complete cupping out. This was both from my own diagnosis and that of the radiographer, and it was thought the second molar should be removed. We removed the tooth and there was absolutely not a particle of absorption. I have seen a number of instances where absorption seemed apparent in the other teeth, where, as a matter of fact, there was none. So I should want the radiographs made from different angles, etc.

Dr. Wilson showed me in San Diego radiograms of a case of an impacted upper canine in a boy of fifteen years of age. The tooth occupied a horizontal position, and apparently one-third of the lateral incisor root was absorbed. He had anticipated making some tooth movement and anchoring to the lateral, but the radiogram caused him to feel he did not have enough support there. I told him I doubted very much if he would find the absorption which the radiogram seemed to show. We have to be very careful, lest we find we have been misled, even though radiograms are made.

In regard to the impacted third molars as shown on the slide we all recognize the impacted canine and its influence in causing malposition of the lateral incisor-especially in the upper arch. The canine lying on the apical end of the lateral causes it to tip into an abnormal position. I think if taken early enough, we will discover, as Dr. Dunn suggests, even earlier than twelve years, - we will find very often the third molar exerts a tremendous influence on the shifting mesially of the other teeth. Invariably the root of the canine is in its normal position, and the cusp of the tooth is in a mesial position.

I hoped the discussion would bring out the question of whether to extract the third molar or the upper second molar. I think it better to lose the upper second molar in some cases, dependent on the condition of the mouth as to caries, etc. When I first advocated the extraction of the upper second molars to the profession in Spokane, they threw up their hands and thought I was too radical. They thought the upper third molar is a useless organ, even after it erupts. I combated that with the argument that it was a great deal like a bad apple in a barrel, and that it is a question of environment. I stated if the third molar takes the place of the second molar, the third molar would have a better chance of being a good tooth than the second molar, as it came at a time in life when the system was not being drained, and it had a better opportunity of being thoroughly calcified than at any other time in life, and thus it should be a better tooth than the second molar. And so I feel in some cases I am doing a patient greater justice in removing the upper second molar rather than the third molar.

Dr. Carter.-I would like to ask Dr. Morehouse in relation to this. Was it a lateral in Dr. Wilson's case?

Dr. Morehouse.-Yes.

Dr. Carter.-What was the position of the lateral in relation to the central?

Dr. Morehouse.-Normal.

Dr. Carter.-In normal position. I was going to suggest an error might be made on account of foreshortening. 